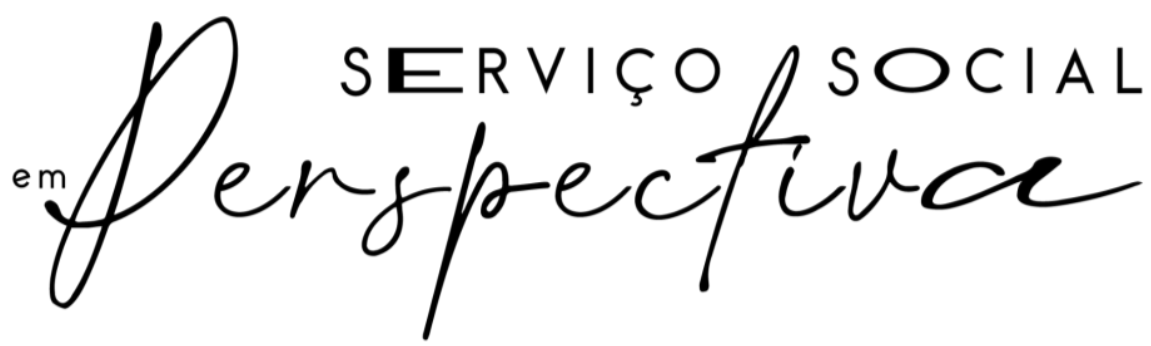

Montes Claros (MG), volume 6, número 1. jan./jun. 2022. I ISSN 2527-1849

\title{
CONFORMAÇÃO DO FENÔMENO DA POPULAÇÃO EM SITUAÇÃO DE RUA E A (DESIPROTEÇÃO SOCIAL NO BRASIL EM TEMPOS DE PANDEMIA
}

\section{CONFORMATION OF THE PHENOMENON OF THE STREET POPULATION AND THE (DIS)PROTECTION IN BRAZIL IN PANDEMIC TIMES}

\author{
Jarina Ébano Avelina Ferraz Alves
}

\begin{abstract}
Resumo: $O$ presente artigo tem por objetivo proporcionar uma reflexão critica sobre a conformação do fenômeno da população em situação de rua nas particularidades brasileiras. problematizar o aumento desse grupo populacional em tempos de crise sanitária. mapeando as políticas públicas voltadas a esse público e quais ações têm sido efetivadas pelo Estado no contexto de crise econômica, social e pandêmica. Por meio de um levantamento exploratório. fundamentado na perspectiva de análise marxista. a partir do estudo em fontes documentais, esse trabalho apresenta indicadores que demonstram as implicações dos determinantes estruturais que condicionam os indivíduos aos espaços das ruas e os fazem permanecer nessa condição. Como poderemos constatar, o fenômeno da população em situação de rua é consequência do processo desigual do modo de produção capitalista e seu processo contraditório que determina a extrema precariedade com a qual essas pessoas subsistem. Perceberemos também a desresponsabilização do Estado, principalmente em meio ao avanço do neoliberalismo, no que diz respeito aos serviços e programas direcionados a essa população, sobretudo quando, apesar de existir uma politica específica para a população em situação de rua, as dificuldades no acesso têm demonstrado o grande percentual de pessoas que não são assistidas pelo poder público.
\end{abstract}

Palavras-chave: População em Situação de Rua. Capitalismo. Questão Social. Estado. Politicas Públicas.

Abstract: This article aims to provide a critical reflection on the conformation of the phenomenon of the homeless population in the Brazilian particularities, problematize the increase of this population group in times of health crisis, mapping the public policies aimed at this public and what actions have been carried out by the State in the context of economic, social and pandemic crisis. Through an exploratory survey, based on the perspective of Marxist analysis, from the study of documentary sources, this work presents indicators that demonstrate the implications of the structural determinants that condition individuals to street spaces and make them remain in this condition. As we can see. the phenomenon of the homeless population is a consequence of the unequal process of the capitalist mode of production and its contradictory process that determines the extreme precariousness with which these people subsist. We will also realize the lack of responsibility of the State, especially amidst the advance of neoliberalism, with regard to services and programs aimed at this population, especially when, despite the existence of a specific policy for the homeless population, the difficulties in access have shown the large percentage of people who are not assisted by the government.

Keywords: Homeless Population. Capitalism. Social issues. State. Public policy.

1 Graduanda do curso de Serviço Social da Universidade Federal de Sergipe. https://orcid.org/0000-0002-46937638 http://attes.cnpabr/2415944739162665 E-mail: jarinafr.br@gmail.com

Artigo submetido em: 22 de outubro de 2021.

Artigo aceito em: 03 de janeiro de 2022.

p. 89-107, DOI: https://doi.org/10.46551/rssp202205 
INTRODUÇÃO

Refletir sobre o fenômeno da população em situação de rua e compreendê-lo como parte consequente das desigualdades sociais intrínsecas à dinâmica do modo de produção capitalista permitem elaborar respostas tais quais não sejam: naturalizando, criminalizando e se conformando com as multifacetadas expressões de mazelas que condicionam essas pessoas aos espaços das ruas. Estar em situação de rua significa encontrar-se marcado por elementos estruturais que determinam um grupo de pessoas à base da esfera socioeconômica e a massa sobrante da população, de modo a manter ativo o exército industrial de reserva ${ }^{2}$ necessário para assegurar a valorização do capital.

O contexto atual do capitalismo, por meio do seu projeto neoliberal que se intensifica cada vez mais, acentua o aumento exponencial da pobreza e do desemprego, fatores essenciais que relacionam o fenômeno da população em situação de rua - enquanto expressão da questão social - à estrutura do capitalismo, contribuindo para o aumento desse grupo populacional. Esse processo tem sido efetivado com a garantia da mediação do Estado que tem cumprido seu papel na contradição capital/trabalho de, por um lado, assistir à população em situação de rua através das políticas públicas lainda que dentro da lógica focalizada e seletival e, por outro lado, garantir a exploração/acumulação, por poucos, da riqueza socialmente produzida.

Verificam-se no cenário de crise sanitária os efeitos ainda mais graves causados para pessoas que, em suas condições de vida, têm nos espaços das ruas o seu local de moradia e trabalho. De modo que a eclosão da pandemia ${ }^{3}$ tem se mostrado não como determinante, e

\footnotetext{
2 Exército industrial de reserva ou superpopulação relativa se refere às pessoas que constituem a parte da classe trabalhadora a qual não permanece no mercado de trabalho formal. Para Marx (2017), essa população pode ser caracterizada em três situações: a primeira, a flutuante; a segunda, latente; e a terceira, a estagnada. Na forma flutuante, os(as) trabalhadores(as) normalmente exercem as atividades nas fábricas ou oficinas de maquinaria e ficam empregados(as) de acordo com o progresso da produção no momento, desse modo, se a produção é crescente, um maior número de trabalhadores(as) permanece ativolas). Se a produção não desenvolve, aumentam os(as) trabalhadores(as) em situação de exército de reserva. Com relação à população latente, são os(as) que esperam o momento de ascensão da produção para migrar para a cidade e vender sua força de trabalho à indústria. E a situação estagnada refere-se aos(as) trabalhadores(as) que, na maioria das vezes, se encontram ativoslas), no entanto, além de ocuparem trabalhos precarizados com baixos salários, exercem atividades em várias esferas da produção, estando sempre disponiveis à exploração do capital.

3 Considerando um novo tipo de coronavírus, a covid-19 é uma doença causada pelo coronavírus, denominado SARS-CoV-2. O início da transmissão dessa doença ocorreu em dezembro de 2019 em Wuhan, na China, logo, disseminou mundialmente, chegando ao Brasil em fevereiro de 2020.
} 
sim, como um fato que apresenta as marcas da crise estrutural do sistema do capital, expondo a situação desumana de miséria na qual a população em situação de rua subsiste, a (des)proteção social do aparato Estatal e a falta de regularidade com a qual as ações de medidas emergenciais foram executadas.

Diante dessa conjuntura, o artigo objetiva problematizar a conformação do fenômeno da população em situação de rua na particularidade brasileira e os fatores que contribuem para a sua constituição e o aumento na cena contemporânea, considerando-se o momento atual da pandemia da covid-19. Para esse intento, do ponto de vista metodológico, além de pesquisa bibliográfica, foram utilizados para análise alguns documentos, tais como I Censo Nacional, levantamentos de indicadores socioeconômicos do Instituto de Pesquisa Econômica Aplicada (lpea) e Política de Inclusão sobre/para a população estudada. $O$ desenvolvimento foi fundamentado teoricamente a partir de uma reflexão crítica dividido em três seções subsequentes a essa introdução, e, por fim, as considerações finais.

\section{POPULAÇÃO EM SITUAÇÃO DE RUA NO BRASIL: UMA EXPRESSÃO DA QUESTÃO SOCIAL}

Ao refletir sobre os determinantes que historicamente vêm conformando o fenômeno da população em situação de rua, é possivel destacar alguns fatores estruturais resultantes das contradições fundamentais postas na relação capital/trabalho. Através desses elementos, compreendemos que a gênese desse fenômeno se instaura enquanto consequência do novo modo de produção, no cenário da chamada "lei geral da acumulação capitalista" (MARX, 2017. p. 835). Desse modo, há coerência em afirmar que a população em situação de rua é consequência da desigualdade social indissociável da acumulação da riqueza socialmente produzida e apropriação privada no contexto capitalista, portanto, se caracteriza como uma expressão da "questão social".

lamamoto (2001) destaca que o debate "questão social" se funda a partir da análise da reprodução ampliada de capital, por meio da exploração da classe trabalhadora, no desenvolvimento de produção material que propõe movimentos nas relações sociais. Logo, esses processos de relações materiais e sociais são intrínsecos. Segundo Marx (2017), o decurso que culmina o início do novo modo de produção (capitalista) teve seu ponto de partida na expropriação de grande parte da população das terras feudais, no século XV. E, por 
expropriados, entende-se que foram separados bruscamente dos seus meios de produção, transformados em trabalhadores "livres".

Libertos, porém, destituidos dos seus meios de produção para a garantia da própria sobrevivência e sem outra possibilidade de escolha, passam a vender a sua mão de obra para os novos possuidores dos meios de produção, os burgueses. Grande parte desses camponeses não conseguiram entrar no mercado de trabalho na mesma velocidade com a qual foram arrancados de suas terras, de modo que se transformaram em "mendigos, assaltantes, vagabundos, [...] na maioria dos casos, por força das circunstâncias." (MARX, 2017, p. 980). Estabelecendo um cenário resultante do movimento de acumulação do capital que gera um número maior de trabalhadores excedentes à produção e reprodução capitalista, um exército industrial de reserva é essencial para sustentar a valorização do capital e manter esse sistema de produção. Dessa forma, o capitalismo em seu desenvolvimento constitui uma massa sobrante na qual a população em situação de rua encontra-se inserida. Assim, além de considerar uma das multifacetadas expressões desse movimento, entendemos que estar em situação de rua é uma determinação na qual essa população é colocada, não por escolha pessoal.

O surgimento dessas classes distintas (trabalhadores versus capitalistas) e o lugar determinado à classe trabalhadora - enquanto parte explorada - intenta a necessidade de pleitear, através das lutas sociais, a sua inclusão no cenário político para conseguir respostas do Estado. Esta, por sua vez, é impactada pelo processo de exploração da força de trabalho a qual potencializa a extração do trabalho não pago em função da reprodução do capitalismo. aprofundando as suas contradições (MARX, 2017). Nesse sentido, desenvolve-se o processo de amadurecimento político e a consciência de classe dos trabalhadores que, enquanto subalternizados, passam a reivindicar mudanças na estrutura social vigente, inclusive com a perspectiva de sua superação. Com marco nos anos de 1848, essa busca por melhores condições de vida deixa evidente que "o confronto principal não era entre 'pobres' e 'ricos', e. sim, entre trabalhadores, operários e patrões, capitalistas; era contra a exploração do trabalho pelo capital" (SANTOS, 2012, p. 43). Desse modo, as lutas de classe são fundantes e constituem a gênese da questão social.

Na cena contemporânea, o modo de produção capitalista naturaliza e intensifica a desigualdade das classes, pautadas na má distribuição da riqueza produzida coletivamente, de modo que culmina nas múltiplas expressões da questão social, tracejada nas velhas formas, 
as quais se manifestam de maneira cada vez mais exacerbada (IAMAMOTO, 2001). Nesse contexto a população em situação de rua se destaca como um grupo heterogêneo que, entre as características em comum, tem em evidência a sua condição de extrema pobreza.

Os moldes da pobreza existiam em sociedades anteriores e, sem suprimir a existência dessa categoria, destacamos que, somente a partir do sistema/produção capitalista, a despeito da possibilidade de superação dessa condição, continuaram os cenários de desigualdades e pobreza de formas ainda mais aprofundadas. O que se tem na sociedade de classes é a riqueza cada vez mais apropriada por poucos, expondo a forma dissociada com a qual a sua produção é executada pelo conjunto da humanidade e apossada pela sua minoria dominante. Portanto, é possivel compreender que a população em situação de rua é colocada enquanto parte do lumpemproletariado para cumprir uma determinação socioeconômica na produção/reprodução do modo de produção capitalista (MARX, 2017).

Portanto, a pobreza (ou pauperismo) é um elemento essencial que relaciona o fenômeno da população em situação de rua à estrutura da sociedade capitalista, e, como consequência da acumulação do capital, obviamente, não estaria na esfera do sistema capitalista a eficácia do seu combate. Assim, as formas de enfrentamento da pobreza no capitalismo não pretendem extingui-la, da mesma maneira que não têm pretensão em eliminar o fenômeno da população em situação de rua.

Ao contextualizar a formação sócio-histórica do Brasil, associamos o surgimento da população em situação de rua ao desenvolvimento urbano no país, proveniente do processo de expansão do capitalismo. No período de passagem para a configuração econômica com sua base industrial, em meados da década 1930, a migração da população rural para os centros urbanos superlota as cidades de forma que não existiam empregos suficientes para todos, assim como a privação de habitações, entre outros elementos, difundindo as expressões da questão social. Nesse contexto, o que se conformava era uma população determinada à situação de pobreza generalizada, moradores de zonas periféricas em condições subumanas.

Morando nas periferias dos grandes centros urbanos e desempregados, restavam poucas alternativas às pessoas, e uma delas era vender mercadorias nos sinais de trânsito ou nas calçadas das cidades. Com o surgimento dessa atividade considerada ilegal pelo Estado, pois sobre ela não se arrecadava tributos, veio a repressão violenta e desumana por parte dos agentes de segurança pública. As pessoas que encontraram na venda destes materiais um meio de sobrevivência passaram a ser perseguidas, muitas vezes presas, a terem suas mercadorias apreendidas e conseqüentemente [sic consequentemente], ficavam sem nada, nem mesmo o dinheiro que haviam investido. 
Sem mais nenhuma opção, só thes restava a rua ou os serviços de abrigo noturno. Portanto, podemos considerar que estavam literalmente nas ruas. (MOVIMENTO NACIONAL DE POPULAÇÃO DE RUA, 2009, p. 173, grifo nosso).

Esses foram (ainda são) os moldes nos quais se conformou (conforma) a população em situação de rua no Brasil. Cidadãos historicamente determinados à condição de extrema pobreza, fortemente criminalizados e estereotipados enquanto mendigos, andarilhos, pedintes, vagabundos, entre outras associações marginalizadas que desconsideram as múltiplas determinações históricas e estruturais as quais subordinam os indivíduos às ruas. As pessoas em situação de rua no Brasil carregam como marca histórica a comparação aos que eram considerados "vadios" na época da colonização do país, principalmente no periodo escravocrata.

É nesse grupo (os "vadios") que, por estigma, está classificada a população em situação de rua. Um segmento visualizado como aqueles que escolhem desperdiçar a sua força de trabalho por motivos individuais, e, por opção própria, estar na massa sobrante da população. Como reforço a essa marginalização estereotipada, verificamos um histórico de normativas legais que, de maneira indireta, instituem penalidades à população em situação de rua, dentre elas, estão o Código Criminal de 1830 (Art. no 295/Cap. IV), o qual instituiu "vadios e mendigos [...] o tipo penal da vadiagem" e o Código de Contravenções Penais de 1941, que criminaliza a mendicância (extinguida das contravenções em 2009) e a vadiagem considerada crime até os dias atuais (RODRIGUES; et al, 2020, p. 25, grifos dos autores). Tais elementos revelam o processo de criminalização da pobreza como um dos determinantes da formação social brasileira, incidindo sobre alguns grupos, entre eles, a população em situação de rua.

Até aqui, observa-se que a dinâmica do modo de produção capitalista instaura e se desenvolve atravessada por várias contradições em seu movimento. Nesse aspecto, à medida em que um crescimento da acumulação do capital, deriva a emergência das crises capitalistas. Para Mészáros (2011), as crises em suas variadas intensidades e duração sustentam a existência do capital e apresentam problemas mais localizados na esfera social. Entretanto, desde 1970 até os dias atuais, a crise que vivenciamos, de acordo com o autor, é substancialmente uma crise estrutural do capital, de modo que seus impactos recaem em todas as esferas da sociedade.

Nesse contexto, a estratégia para que o processo de acumulação do capital permaneça contínuo é o projeto neoliberal, que naturaliza as contradições e desigualdades sociais provenientes do modo de produção capitalista. $\bigcirc$ neoliberalismo conta com a intervenção do 
Estado, principalmente na economia, através de ajustes que favorecem a classe dominante e com a sustentação de um movimento de contrarreformas determinadas à diminuição e/ou fim dos direitos sociais, por meio do enxugamento dos gastos do Estado sobre essas garantias (BEHRING; BOSCHETTI, 2011). O avanço neoliberal amplia desemprego, informalidade, bem como a pauperização de massas inteiras de trabalhadores, de modo que, na linha reta desses efeitos, encontra-se a população em situação de rua, assim, as formas criminalizadoras as quais impactam essas pessoas tendem a se intensificar ainda mais.

\section{PROTEÇÃO SOCIAL: O (NÃO) ACESSO DAS PESSOAS EM SITUAÇÃO DE RUA}

Foi a partir do viés religioso de cunho caritativo que se iniciaram as discussões sobre a população em situação de rua no Brasil, a priori, por meio da Organização de Auxílio Fraterno (OAF) e, posteriormente, da Pastoral do Povo de Rua vinculada à igreja católica que executavam ações sociais direcionadas a essas pessoas. $O$ desenrolar do debate político e público sobre esse fenômeno se deu no ano de 1992, durante a reunião da Cúpula Mundial do Meio Ambiente, que ocorreu na cidade de São Paulo (SPOSATI, 2009).

Algumas necessidades, sobretudo as imediatas, (apenas) de uma parcela da população em situação de rua eram respondidas por meio das ações de caridade da igreja, no entanto, não alcançavam a todos. Nesse sentido, surgiram alguns movimentos articulados sem contribuição do poder público. Um exemplo são os catadores de materiais reciclados que "deram origem a associações, cooperativas e, posteriormente, ao Movimento Nacional dos Catadores de Materiais Recicláveis (MNCR)." (MOVIMENTO NACIONAL DE POPULAÇÃO DE RUA, 2009, p. 177).

Essas iniciativas foram causando tensões no processo de reivindicações para políticas públicas direcionadas à população em situação de rua. Com a cooperação de algumas instituições a exemplo da Pastoral do Menor, bem como de alguns projetos de auxilio a crianças e adolescentes em situação de rua, articulados com o apoio do Fundo das Nações Unidas para a Infância (Unicef), subsidiaram a base para a construção do Movimento Nacional de Meninos e Meninas de Rua (MNMMR). Além disso, tais instituições, em conjunto, realizaram, entre os anos 1981 e 1992 a Semana Ecumênica do Menor, "que reuniu aproximadamente mil pessoas na defesa dos 'meninos de rua' e na organização da luta por direitos de cidadania para esse segmento" (BRASIL, 2011, p. 15), aprofundando o debate político. 
Mediante as estratégias dessas organizações, a população em situação de rua foi ocupando espaços em busca de melhora na qualidade de vida, acesso a serviços, entre outros. No entanto, mesmo após a promulgação da Constituição Federal de 1988 e o progresso da Assistência Social, que passa de um viés caritativo para direito social garantido pelo tripé da seguridade social ${ }^{4}$, o que se efetivava era (ainda él a omissão do Estado.

Um marco de grande repercussão que contribuiu para engajar ainda mais a visibilidade da luta da população em situação de rua foi o massacre da Praça da Sé, no Centro do município de São Paulo,

Em 19 de agosto de 2004 ocorreu um fato que jamais vamos esquecer. Um episódio que ficou conhecido como a chacina da Praça da Sé, onde sete moradores de rua foram brutalmente assassinados, sem nenhum motivo que justificasse tamanha covardia. A noticia correu o país provocando grande comoção social, mas apenas isso. O que se pode extrair de positivo dessa tragédia é a maior visibilidade ao grande contingente de pessoas vivendo nas ruas, entregues à própria sorte, sem nenhum amparo ou proteção. A chacina da Praça da Sé lembrada sempre com muita tristeza por todos nós, moradores e ex-moradores de rua, é um marco histórico em nossa luta por direitos [...]. (MOVIMENTO NACIONAL DE POPULAÇÃO DE RUA, 2009, p. 23).

Episódio lembrado até os dias atuais por fonte de notícias, entidades e movimentos sociais, como uma data que pronuncia homenagem referente ao dia nacional de luta da população em situação de rua. No mesmo ano do acontecimento, houve a instituição do Movimento Nacional de População de Rua (MNPR). Na sequência, o I Encontro Nacional sobre o tema, que resultou na alteração da Lei Orgânica de Assistência Social (LOAS), Lei no 8.742. de 7 de dezembro de 1993, alterada em 2005 para a inserção da população em situação de rua enquanto público-alvo na garantia dos programas e atendimentos do Sistema Único de Assistência Social (Suas).

O I Encontro Nacional também contribuiu para uma importante articulação na elaboração do projeto da primeira pesquisa censitária ${ }^{5}$, executada posteriormente entre os anos 2007 e 2008. A pesquisa objetivou traçar o perfil socioeconômico das pessoas em situação de rua no Brasil através de um levantamento que abordou 71 cidades (BRASIL, 2009). Um dos mais

\footnotetext{
4 Saúde como direito universal, previdência com base na prévia contribuição, e assistência social para os que dela necessitar.

${ }^{5}$ Realizada pelo Instituto Meta, por meio de um acordo de cooperação entre a Secretaria de Avaliação e Gestão da Informação (SAGI) em parceria com a Secretaria Nacional de Assistência Social (SNAS), ambas do Ministério do Desenvolvimento Social (MDS - atual Secretaria Especial do Desenvolvimento Social vinculada ao Ministério da Cidadania) e a Organização das Nações Unidas para a Educação, a Ciência e a Cultura (UNESCO).
} 
importantes resultados dessa pesquisa foi subsidiar a construção da Política Nacional para Inclusão Social da População em Situação de Rua, instituída pelo Decreto no 7.053/2009, "com fins a orientar a construção e execução de políticas públicas voltadas a esse segmento social, historicamente, à margem das prioridades dos poderes públicos." (SERAFINO; LUZ, 2015, p. 76).

A politica de inclusão pretende abranger questões relacionadas ao grupo de pessoas que fazem das ruas o seu espaço de sobrevivência e moradia, ressaltando a necessidade de estabelecer politicas públicas para favorecer o desenvolvimento/ascensão social destas. Destaca-se como princípios: a garantia da cidadania e direitos humanos, a dignidade da pessoa humana, o direito à permanência na cidade, a não discriminação e a extinção de qualquer atitude violenta ou humilhante atribuida de preconceitos (BRASIL, 2008).

Todavia, apesar dos avanços, o que se tem observado no Brasil é que não existem políticas públicas e/ou um sistema de proteção social que alcancem toda a população em situação de rua. Além de seguir a lógica de seletividade, algumas ações executadas não são integrais, e, de medida temporária, a exemplo das casas de acolhimento, albergues e repúblicas, evidenciando que "a relação da população em situação de rua com as políticas sociais é uma relação de cobertura infima, de quase completa exclusão." (SILVA, 2009, p. 186).

Considerando que essas pessoas fazem parte da massa excedente que assegura a existência da produção e reprodução do capital, e, portanto, inerente a esse sistema, o papel das políticas sociais direcionadas à população em situação de rua, e outros segmentos, acompanha uma contraditória dualidade. Por um lado, podem ser entendidas como formas de conquistas respondendo à questão social; por outro lado, cumprem um papel fundamental de manter a ordem societária, quando não efetiva o acesso universal garantido constitucionalmente. Conforme afirma Pastorini,

[...] as politicas sociais, além de constituirem um instrumento redistributivo, ao mesmo tempo, e principalmente, cumprem outras funções: politicas e econômicas - esta última não restrita exclusivamente aos elementos redistributivos e de prestação de assistência e serviços [...] pelo contrário, que é necessário analisar a sua contraparte política como mecanismo de legitimação da ordem; [...] (1997, p. 86).

Observa-se que as políticas sociais são efetivadas pelo Estado com a função de atenuar as desigualdades sociais, entretanto, salientamos que não é mera concessão do Estado. Conforme já mencionado, são respostas à questão social, além disso, "terão um caráter 
compensatório, paliativo e corretivo" (PASTORINI, 1997, p. 86, grifos da autora), ou seja, não têm perspectiva de proteção social universal.

Nesse sistema de não proteção e dualidade das políticas sociais, entendemos que o papel cumprido pelo Estado é essencial, desempenhando mediação na contradição capital/trabalho, "[...] transformando as reivindicações em leis que estabeleciam melhorias tímidas e parciais nas condições de vida dos trabalhadores, sem atingir, portanto, o cerne da questão social" (BEHRING; BOSCHETTI, 2011, p. 63). Como intermediário, verifica-se que o Estado, quando intervém, não tem uma lógica de distribuição da riqueza produzida pelo conjunto de trabalhadores, é tão somente para manter essa classe na massa reserva. assegurando as relações capitalistas, seja pela atenuação de eventuais conflitos, seja pela garantia mínima das condições de reprodução da força de trabalho, "matéria-prima" essencial à valorização do capital. Do mesmo modo quando trata de forma omissa as demandas da população em situação de rua, não por falta de conhecimento, mas pela necessidade em ter uma massa excedente sempre disponível à produção e reprodução do capital. Nesse sentido, por ação ou omissão, o Estado opera como um articulador das condições gerais da produção capitalista, buscando proporcionar insumos necessários à sua contínua reprodução, sobretudo no contexto atual, demarcado pelos impactos da crise capitalista.

De acordo com Pastorini (1997), as políticas sociais, por meio da sua função social, contemplam a população em extrema pobreza através de programas de transferência de renda, assim como benefícios sociais para complementar salário, e, em sua maioria, o públicoalvo é de pessoas que não conseguem entrar no mercado formal de trabalho. Ainda assim, quando direcionadas à população em situação de rua que, em maioria, está nas atividades informais, "[...] são poucas as ações de proteção do Estado para essa população. As iniciativas existentes limitam-se à área de assistência social, que, até agora, têm adotado os critérios de proximidade e inaptidão ao trabalho, de forma rigida, o que tem restringido direitos" (SILVA, 2009, p. 194).

No tocante a sua função econômica, as políticas sociais contribuem para manter o baixo custo dessa força de trabalho, com o seu direcionamento para a superpopulação relativa. Com relação à função política, estabelece por meio do controle social a sensação de participação e democracia. Essas três atribuições das politicas sociais articuladas, tendo o Estado como mediador, amenizam as tensões das lutas de classes, camuflando as expressões da questão social, para assim manter a acumulação do capital (PASTORINI, 1997). É por essa 
perspectiva que as políticas sociais não têm uma lógica de proteção social universal, sobretudo no contexto do neoliberalismo, de modo que uma das suas principais funcionalidades é gerir essa força de trabalho reserva.

\section{AUMENTO DO FENÔMENO EM TEMPOS DE CRISE SANITÁRIA}

Os dados relativos ao fenômeno da população em situação de rua no Brasil indicam que, em 2007, existiam 31.922 pessoas nessa condição, de acordo com os resultados do I Censo Nacional. Consideramos, aqui, de acordo com o conceito utilizado no resultado da pesquisa para definição da população em situação de rua:

[...] grupo populacional heterogêneo que possui em comum a pobreza extrema, os vínculos familiares interrompidos ou fragilizados e a inexistência de moradia convencional regular, e que utiliza os logradouros públicos e as áreas degradadas como espaço de moradia e de sustento, de forma temporária ou permanente, bem como as unidades de acolhimento para pernoite temporário ou como moradia provisória (BRASIL, 2008).

Em 2015, com base na estimativa do Instituto de Pesquisa Econômica Aplicada (IPEA), houve um aumento substancial desse fenômeno para $101.854^{6}$ pessoas em situação de rua no Brasil, e maior ainda em 2020, quando se verifica $221.869^{7}$ pessoas em situação de rua no país. É importante ressaltar, conforme a estimativa apresentada, que o número de pessoas em situação de rua nesse periodo (em cinco anos) mais que dobrou, evidenciando o descaso do Estado com o expressivo crescimento do fenômeno e a não efetivação de políticas públicas que pudessem atenuar sua manifestação, sobretudo nos governos Temer e bolsonarista.

No tocante ao perfil, com base na pesquisa nacional, $82 \%$ são homens, com predominância na faixa etária que corresponde a 53\% entre 22 e 44 anos de idade, e, no que se refere à cor, $67 \%$ dos entrevistados se autodeclaram pardos ou pretos. Como principal fonte de sobrevivência, $70,9 \%$ relatam que a sua remuneração é proveniente dos trabalhos informais, tais como: flanelinha, catador de materiais recicláveis, vendedor ambulante, entre

\footnotetext{
6 (NATALINO, 2016).

7 (NATALINO, 2020)
} 
outros. Além disso, constatou-se que $88,5 \%$ das pessoas em situação de rua no Brasil não recebem benefícios do Governo (BRASIL, 2009).

Esses resultados delineiam as implicações dos determinantes estruturais resultantes do modo de produção capitalista, cuja sustentação é a exploração, constituição da superpopulação relativa e desigualdade de classes, que não só condicionam as pessoas à situação de rua como mantêm o aumento desse fenômeno. Em concordância com Silva (2009), questões que são características dos grandes centros urbanos na contemporaneidade como o aumento dos indicadores de pobreza, expansão da informalidade, crescimento do trabalho precário e desemprego, são essencialmente relevantes nas determinações que conformam o fenômeno da população em situação de rua e seu crescimento.

No contexto de crise estrutural do capitalismo, que decorre desde a década de 1970 e perdura até os dias atuais (MÉSZÁROS, 2011: NETTO; BRAZ, 2012), as estratégias utilizadas para amortecer essa crise do capital, por meio do neoliberalismo, sustentam uma movimentação de contrarreformas determinadas à diminuição e/ou extinção dos direitos sociais, fundamentalmente, enxugando os gastos do Estado direcionados a essas garantias. Isso atinge diretamente a classe trabalhadora com os mais perversos impactos desse retrocesso de direitos, e de forma ainda mais aguçada à população em situação de rua.

As condições de vida nas quais essas pessoas são submetidas não são compativeis com os procedimentos burocráticos exigidos para a sua inserção nos serviços das políticas públicas, em suas diversas esferas (saúde, educação, segurança alimentar, moradia, assistência social). É possivel afirmar isso a partir da exposição de Silva, quando diz que

As chamadas "exigências formais" para poder participar dos programas que dão corpo às politicas sociais geralmente constituem limites de acesso a eles pelas pessoas em situação de ruas. Uma das "exigências formais" é a apresentação e documentos de identificação pessoal. No entanto, são poucas as pessoas em situação de rua que os têm. (2009, p. 175).

Embora existam garantias constitucionais e ainda uma Política Nacional de Inclusão para a População em Situação de Rua ${ }^{8}$, as exigências burocráticas que são requeridas, para o acesso dessa população, tornam as políticas sociais quase inacessiveis - conforme supracitado, de

\footnotetext{
8 Tem por objetivo afirmar o compromisso do Estado na garantia de direitos da população em situação de rua. Deve-se existir articulação entre as redes e diversas politicas de saúde, educação, segurança alimentar, trabalho. renda, entre outras (BRASIL, 2008).
} 
acordo com o censo, a maior parte $(88,5 \%)$ da população em situação de rua no Brasil não recebe benefícios do Governo. Somando ao retrocesso neoliberal, resulta na realidade vivenciada por esse público muito diferente do que se expressa legalmente. Isto posto observa-se que são muitas as restrições das pessoas em situação de rua no acesso "às políticas sociais de saúde e educação e são extensivas às demais políticas sociais, como assistência social, habitação, trabalho e renda" (SILVA, 2009, p. 178)

Além das dificuldades burocráticas que esse público enfrenta para o acesso às politicas públicas, é possivel integrar também: a ausência de articulação nas esferas das políticas sociais, as ações e programas sociais com dinâmicas inadequadas, a inexistência de capacitação dos servidores para atendimento/acolhimento da população em situação de rua. Logo, a falta de habilidade, no que se refere a esse público, soma-se também ao "preconceito social que estigmatiza essas pessoas como 'vagabundos', 'desordeiros', 'preguiçosos', e 'bandidos', fazendo com que sejam consideradas não merecedoras do acesso aos direitos sociais" ISILVA, 2009. p. 176).

Segundo Tiengo (2018), a população em situação de rua permanece exposta a condições desumanas de sobrevivência, que se apresenta através da escassez das políticas públicas, como também a falta de higiene, exposição a doenças, vulnerabilidade à violência nas ruas, carência de alimentos, dentre tantas outras violações contra esse público. Percebe-se que as politicas sociais ainda não conseguiram ser suficientes e concretamente ofertar melhorias na qualidade de vida da classe pauperizada, sobretudo, da população em situação de rua. Isto é. ainda nos limites possíveis do desenvolvimento capitalista, têm sido impossibilitadas conquistas mínimas de natureza civilizatória a esses sujeitos, situação que se agrava em tempos de avanço do neoliberalismo e desmonte das políticas sociais.

O sistema capitalista em seu estágio neoliberal, além de não amparar, naturaliza a condição de pobreza das pessoas em situação de rua, por meio de uma ideologia que culpabiliza o indivíduo, com o debate de que essa condição foi dada por escolha pessoal e não pela dinâmica do modo de produção capitalista. Nessa lógica, há uma desresponsabilização do Estado de que "não será o agente fundamental na proteção das 'populações pobres' ou de 'risco social', mas as próprias comunidades vulneráveis mobilizarão seus recursos para reverter a situação, numa espécie de 'empoderamente' [sic empoderamento]" (SIQUEIRA, 2013, p. 121). Esse empoderamento considera "um projeto (de sociedade) em aberto, orientado para as pessoas enquanto agentes e que respeita a diversidade humana e a liberdade de escolha. 
Nesse projeto, a pobreza e a tirania são os principais entraves a serem enfrentados" ISIQUEIRA, 2013, p. 138).

Nesse sentido, são os próprios individuos que, em grupos de lutas sociais, devem unir forças em prol de um objetivo comum para a melhoria da sua condição social. No entanto, essa correlação de forças não busca superar a ordem societária que mantém a acumulação de capital daqueles que possuem os meios de produção, de modo que não extinguir a ordem dominante atual é permanecer na lógica capitalista que "gera acumulação, por um lado, e pobreza por outro; jamais eliminaria nem um nem outro" (SIQUEIRA, 2013, p. 164).

$\mathrm{Na}$ conjuntura de avanço neoliberal, diante dos mais diversos retrocessos das políticas públicas, verifica-se maior incidência do estigma das pessoas em situação de pobreza e naturalização dessa condição. Por outro lado, tal cenário tende ao aprofundamento mediante a emergência da crise sanitária da covid-19, surgindo não como determinante, mas enquanto evento que contribui para aprofundar as expressões da questão social e o aumento do fenômeno da população em situação de rua. Para Tiengo (2021), o crescimento exacerbado desse fenômeno na pandemia é consequência direta do desemprego, decorrente da crise estrutural, que sempre foi um elemento o qual caracteriza a população em situação de rua, e agora, em tempos de crise sanitária, se intensifica após o isolamento social.

Desde março de 2020, quando houve a eclosão da covid-19 no Brasil, circulam várias notícias sobre pessoas em situação de rua, suas condições de vida, a falta de políticas públicas que sejam efetivadas em tempos de calamidades pública e/ou de emergência, além do aumento desse fenômeno, evidenciando a (des)proteção social do Estado, apesar da política de inclusão e atenção específica às demandas desse grupo. A expansão da pandemia expõe - grande desafio para efetivar as políticas de atenção a essa população por causa da realidade de vida dessas pessoas, sobretudo, em tempos de aumento desse público, de forma que verifica o quanto as medidas emergenciais efetivadas não são suficientes, conforme exposto no levantamento do lpea?

As orientações de distanciamento social, medidas de higiene e não circulações, feitas pela Organização Mundial de Saúde (OMS) como forma de prevenção no periodo da pandemia,

\footnotetext{
9 Levantamento de dados sobre as medidas municipais emergenciais, realizado por meio de uma pesquisa documental em sites governamentais além das análises sobre as percepções de atores-chave no que se refere ao tema a partir de entrevistas semiestruturadas com gestoras e gestores, representantes do Judiciário e da sociedade civil, assim como pesquisadores na área das politicas públicas para a população de rua ISILVA; NATALINO; PINHEIRO, 2020).
} 
evidenciam alguns aspectos que impactam e expõem as circunstâncias reais vividas pela população em situação de rua. $O$ primeiro é a falta de moradia, quando a OMS instrui que as pessoas fiquem em casa. $O$ que fazem as pessoas que não têm casa? Dentro dessa falta de estrutura, entram também as medidas de higiene, como lavar as mãos, usar álcool em gel, entre outras, que não são compativeis com as condições objetivas dos indivíduos que utilizam as ruas como seu espaço de moradia. Outros elementos são a predominância nos trabalhos informais e as doações de alimentos nas ruas, que, em alguma medida, sustentam a subsistência dessas pessoas. Sem circularem nas ruas, como vão fazer para obter renda? Sem as doações, como vão se alimentar?

Esses questionamentos apontam as condições de extrema vulnerabilidade determinadas à população que faz das ruas o seu espaço de moradia e sobrevivência. Sinalizam também a ausência que o poder público vem exercendo no que diz respeito a essas pessoas. Conforme Silva, Natalino e Pinheiro (2020, p.08) relatam: "As informações sobre essa população, contudo, carecem ainda de maior regularidade e dimensão nacional." Ponderamos ainda que não só as informações, como também a execução de ações voltadas a esse grupo de pessoas, precisam ser efetivadas em conformidade com os princípios da política de inclusão para a população em situação de rua no Brasil.

Diante dessas circunstâncias de crise sanitária, a partir das orientações de algumas instituições ${ }^{10}$, foram estabelecidas medidas de emergência para o enfrentamento da pandemia junto à população em situação de rua. Segundo a portaria no 69, de 14 de maio de 2020, foi determinado aos municípios: prestar informações às pessoas em situação de rua acerca da covid-19; orientações sobre os locais de atendimento do Sistema Único de Assistência Social (Suas) e Sistema Único de Saúde (SUS), os horários e formas de acesso aos serviços; distribuição de itens básicos de sobrevivência a exemplo de alimentação, água potável, produtos de higiene, limpeza, máscara facial, vestuário e outros; alternativas relacionadas a medidas de acolhimento regular e provisório, assim como espaços e materiais para a higiene pessoal dessa população; inclusão no Cadastro Único; e acesso a programas sociais, benefícios e auxilio emergencial criado no contexto da pandemia (BRASIL, 2020).

O levantamento do lpea aponta que existem diversos desafios os quais limitam as ações emergenciais (SILVA, NATALINO, PINHEIRO, 2020). Além do aumento da população em

10 Defensoria Pública da União (DPU). Ministério da Mulher. Familia e Direitos Humanos (MMFDH), Conselho Nacional de Direitos Humanos (CNDH), entre outras. 
situação de rua, o pouco número de vagas nos abrigos temporários é disponibilizado de acordo com a lógica de seletividade que prioriza os que estão em maior situação de miséria. Esses espaços, em sua maioria, não cumprem as condições sanitárias no que se refere à quantidade de pessoas alojadas e ao distanciamento social.

Outro ponto primordial é a privação para testagem da população em situação de rua. No que se refere à transferência de renda, o acesso ao auxilio emergencial por parte das pessoas em situação de rua tem sido inviável por causa da falta de documentação, acesso à tecnologia de informação e aos Bancos (SILVA, NATALINO, PINHEIRO, 2020). Vale destacar que a crise pandêmica não criou essas situações, sempre houve escassez nas politicas voltadas a essas pessoas, seletividade, falta de acesso, a pandemia tem apenas explicitado. $\bigcirc$ que se demonstra, entretanto, é que, em um contexto de crise sanitária, tais situações localizam-se em um cenário de ainda maior gravidade, e que expõe a população em situação de rua a um processo de acentuação de violação de direitos.

\section{CONSIDERAÇÕES FINAIS}

Por meio de uma reflexão crítica, a discussão do fenômeno da população em situação de rua no Brasil é entendida enquanto uma expressão da questão social, tendo em vista que as suas multifacetadas manifestações são consequências do processo desigual em que estrutura o modo de produção capitalista. Apontamos alguns determinantes construidos historicamente, compreendidos como elementos estruturais naturalizadores das condições de vida das pessoas que fazem das ruas seu espaço de moradia e sobrevivência. Dentre eles, encontram-se a pobreza e o desemprego, que se aguçam ainda mais em tempos de crise estrutural do capital e avanço do projeto neoliberal, e são fundamentalmente relevantes nas determinações que conformam o fenômeno da população em situação de rua e seu crescimento na atualidade.

Essa ampliação, principalmente após a crise sanitária da covid-19, evidencia as condições de extrema precariedade nas quais essas pessoas vivem, bem como a ausência que o Estado tem exercido no que concerne às demandas dessa população. Verificamos essa omissão quando o primeiro e único Censo Nacional é efetuado há mais de duas décadas (demonstrando 
a desresponsabilização do Estado acerca do aprofundamento no diagnóstico do perfil socioeconômico dessa população). E, ainda, na regularidade da execução de ações voltadas a esse público, quando mesmo em situações de calamidade na qual estamos vivendo desde 2020, o levantamento referente às medidas de urgência mostrou que as ações do Estado são incapazes de alcançar de forma universal a população em situação de rua ISILVA, NATALINO, PINHEIRO, 2020).

É importante ressaltar que sinalizamos a pandemia não como um elemento determinante. mas como um fator que acentua as expressões da crise econômica e social que estrutura a sociedade, impactando diretamente as pessoas em situação de rua. Uma população composta por jovens, majoritariamente negros, que têm por ocupação predominantemente os trabalhos informais em razão das marcas do desemprego estrutural, não acessam as políticas públicas tendo em vista as condições de vida não compativeis com as formas burocráticas que obstaculizam seu alcance. Ademais, os desafios enfrentados por essa população, e que foram expostos de maneira breve neste trabalho, precisam ser ainda mais discutidos e, de maneira necessária, explicitados em outras pesquisas, sobretudo para que não se perca o foco de uma luta por igualdade e plena liberdade das amarras de opressão desse sistema.

\section{REFERÊNCIAS}

BEHRING, Elaine Rossetti; BOSCHETTI, Ivanete. Política Social: fundamentos e história. São Paulo: Cortez, 9a ed., 2011.

BRASIL. Política nacional para Inclusão Social da População em situação de rua. Brasilia, DF: Ministério do Desenvolvimento Social, 2008.2 Disponivel em http://www.recife.pe.gov.br/noticias/arquivos/2297.pdf. Acesso em: 20 fev. 2021.

BRASIL. Ministério do Desenvolvimento Social e Combate à Fome. Rua: aprendendo a contar: Pesquisa Nacional sobre a População em Situação de Rua. Brasília. DF: Secretaria de Avaliação e Gestão da Informação, Secretaria Nacional de Assistência Social, 2009.

BRASIL. Ministério do Desenvolvimento Social e Combate à Fome. Secretaria Nacional de Assistência Social. Orientações Técnicas Centro de Referência Especializado para População em Situação de Rua. SUAS e População em Situação de Rua, v. 3. Brasilia, 2011.

BRASIL. Ministério da Cidadania/Secretaria Especial do Desenvolvimento Social/Secretaria Nacional de Assistência Social. Recomendações gerais para a garantia de proteção social à população em situação de rua, inclusive imigrantes, no contexto da pandemia do novo Coronavírus, Covid-19. PORTARIA № 69. DE 14 DE MAIO DE 2020. Disponivel em: https://www.in.gov.br/web/dou/-/portaria-n-69-de-14-demaio-de-2020-257197675. Acesso em: 30 jun. 2021. 
IAMAMOTO, Marilda Vilela. A questão social no capitalismo. Revista Temporalis. Associação Brasileira de Ensino e Pesquisa em Serviço Social, n. 3, jan. / jul., 2001. Brasília: ABEPSS, 2001.

MARX, Karl. O Capital. Livro I: o processo de produção do capital. Tradução: Rubens Enderle. São Paulo: Boitempo, 2017.

MÉSZÁROS, István. Para além do capital: rumo a uma teoria da transição / István Mészáros; tradução Paulo Cezar Castanheira, Sérgio Lessa. - 1.ed. revista. - São Paulo: Boitempo, 2011.

MOVIMENTO NACIONAL DE POPULAÇÃO DE RUA. População de rua: vidas e trajetórias. In: CUNHA, Júnia Valéria Quiroga da: RODRIGUES, Monica (org.). Rua: aprendendo a contar. Pesquisa Nacional sobre a População em Situação de Rua. Brasilia, DF: Ministério do Desenvolvimento Social e Combate à Fome. 2009

NATALINO. Marco Antônio Carvalho. Estimativa da População em Situação de Rua no Brasil. Instituto de Pesquisa Econômica Aplicada (IPEA), 2016. Disponivel em http://www.ipea.gov.br/portal/images/stories/PDFs/TDs/26102016td_2246.pdf. Acesso em: 20 fev. 2021.

NATALINO, Marco Antônio Carvalho. Estimativa da população em situação de rua no Brasil (setembro de 2012 a março de 2020). 2020. Disponivel em http://repositorio.ipea.gov.br/bitstream/11058/10074/1/NT_73_Disoc_Estimativa\%20da\%20populacao\%2 0em\%20situacao\%20de\%20rua\%20no\%20Brasil.pdf. Acesso em: 12 fev. 2021.

NETTO, José Paulo: BRAZ, Marcelo. Economia política: uma introdução crítica. Cortez: São Paulo, 2012.

PASTORINI, Alejandra. Quem mexe os fios das politicas sociais? Avanços e limites da categoria "concessão-conquista". Serviço Social \& Sociedade, n. 53, p. 80-101. São Paulo, 1997.

RODRIGUES, Igor de Souza; et al. A Gênese Social da Situação de Rua no Brasil. In: Cidadãos em situação de rua: dossiê Brasil, grandes cidades. RODRIGUES, Igor; FERNANDES, Dimitri Cerboncini (org.). Curitiba: CRV, 2020. p. 23-49.

SANTOS, Josiane Soares. "Questão social": particularidades no Brasil. São Paulo: Cortez, 2012.

SERAFINO, Irene; LUZ, Lila Cristina Xavier. Política para a população adulta em situação de rua: questões para debate, 2015. Disponivel em http://www.scielo.br/pdf/rk/v18n1/1414-4980-rk-18-01-00074.pdf. Acesso em: 22 fev. 2021.

SILVA, Maria Lúcia Lopes da. Trabalho e população em situação de rua no Brasil. São Paulo: Cortez, 2009

SILVA, Tatiana Dias; NATALINO, Marco; PINHEIRO, Marina Brito. População em situação de rua em tempos de pandemia: um levantamento de medidas municipais emergenciais. Nota técnica no 74, IPEA. 2020. Disponivel em 〈https://www.ipea.gov.br/portal/images/stories/PDFs/nota_tecnica/200610_nt_74_diset.pdf>. Acesso em: 30 jun. 2021

SIQUEIRA, Luana. Pobreza e serviço social: diferentes concepções e compromissos políticos. São Paulo: Cortez, 2013. 
Conformação do fenômeno da população em situação de rua e a (des)proteção social no Brasil em tempos de pandemia

SPOSATI, Aldaíza. Os caminhos do reconhecimento de direitos da população em situação de rua: de indivíduo a cidadão. In: BRASIL. Ministério do Desenvolvimento Social e Combate à Fome. Rua: aprendendo a contar: Pesquisa Nacional sobre a População em Situação de Rua. Brasília, DF: MDS; Secretaria de Avaliação e Gestão da Informação, Secretaria Nacional de Assistência Social, 2009.

TIENGO, Verônica Martins. O fenômeno população em situação de rua enquanto fruto do capitalismo, 2018. Disponivel em http://dx.doi.org/10.15448/1677- 9509.2018.1.29403. Acesso em: 12 fev. 2021.

TIENGO, Verônica Martins. POLÍTICAS PÚBLICAS EM TEMPOS DA PANDEMIA DE COVID-19: dinâmicas, contradições e enfrentamentos em defesa da vida e dos direitos. A pandemia e seus impactos para a população em situação de rua. Disponível em: http://www.periodicoseletronicos.ufma.br/index.php/rppublica/article/view/17332. Acesso em: 30 jun. 2021. 